\title{
INTEGRATION OF HISTORICAL GIS DATA IN A HBIM SYSTEM
}

\author{
N. Bruno ${ }^{a *}$, F. Rechichia, ${ }^{\mathrm{a}}$, C. Achille ${ }^{\mathrm{b}}$, A. Zerbi ${ }^{\mathrm{a}}$, R. Roncella ${ }^{\mathrm{a}}$, F. Fassi ${ }^{\mathrm{b}}$ \\ ${ }^{a}$ Dept. of Engineering and Architecture, University of Parma, Parco Area delle Scienze 181A, 43124, Parma, Italy - \\ (nazarena.bruno, riccardo.roncella, andrea.zerbi)@unipr.it, fabrizio.rechichi@studenti.unipr.it \\ b 3D Survey Group, Dept. of Architecture, Built environment and Construction engineering (ABC), Politecnico di Milano, Italy \\ (cristiana.achille, francesco.fassi)@polimi.it
}

\section{Commission IV, WG IV/7}

KEYWORDS: HGIS, HBIM, Cultural Heritage, Database, Web GIS

\begin{abstract}
:
The integration between BIM (Building Information Modeling) and GIS (Geographic Information System) is currently a highly debated research topic. However, the effective integration of the two workflows in a unique information system is still an open research field, especially when dealing with Cultural Heritage $(\mathrm{CH})$.

The paper describes an ongoing research on the development of a web information system able to integrate BIM and GIS data, with particular focus on the analysis of the historicized city and its main buildings over time. Three main aspects, in particular, are considered more relevant: (i) conceptual data organization to integrate GIS and BIM in a single environment; (ii) integration of data belonging to different historical periods for analyses over time (4D); (iii) integration into the system of datasets already structured in pre-existing HGIS and HBIM.

Most (if not all) of the attributes must be linked with both 2D and 3D entities. The system should be queryable and with the possibility to edit the information regardless of the actual focus of the current user, either if he is more BIM or GIS oriented. This is one of the main requirement for the system not to be just a simple viewer of BIM and GIS data in a unique software environment. The system can manage, from a spatial point of view, different scales of detail, allowing the connection between data from the architectural scale to the territorial one and, from a temporal point of view, data belonging to different periods. All these features have been designed to meet, in particular, the requirements of $\mathrm{CH}$ and realize a Historical BIM-GIS system. Besides, the web architecture allows sharing information even between actors with different digital skills, without the need for specific software installed, and ensures portability and access from mobile devices.
\end{abstract}

\section{INTRODUCTION}

The Building Information Modeling methodology is increasingly used to manage models and information also in the world of Cultural Heritage, according to the widespread management process recognized as Historical BIM.

HBIM allows the structuring of historical and technicalconstruction information in a parametric digital 3D model, facilitating the storage and consultation of useful data for multiple purposes and activities. The management of architectural heritage objects through HBIM has received a boost thanks also to the progressive adoption of national (e.g. UNI $11337 / 2017$ in Italy) and international (e.g. EUPPD 2014/24 and ISO 19650-1,2:2018) standards and regulations, which are destined to become the reference standard for all projects, even for built heritage. BIM has had a growing impact in the new construction sector, thanks to the characteristics that allow to acquire, update and exchange information during the entire life cycle of a building. These functions are also supportive in the case of existing buildings and/or belonging to Cultural Heritage field. The main difference is that in the latter case, the building already exists, therefore, the first activity to be carried out is related to its documentation using a detailed survey. In this sense, the contribution of the survey techniques offered by geomatics is remarkable, in particular thanks to laser scanning, photogrammetry and the possibility of their integrated use. It is possible to acquire data of shape and position of even very complex objects, thus facilitating the creation of BIM parametric models, according to the specific levels of development and detail for restoration and conservation projects.

GIS systems, instead, are exploited for their analytical skills and potential to support activities in different fields. Just to name a few, GIS plays a central role in activities such as urban and territorial planning, in the management of paperwork for the Public Administration, or in the computerization of cartography for different purposes (thematic cartography) nowadays.

The GIS and BIM systems, by their nature, manage information of different types and with different levels of detail, which entails geometric and semantic interoperability problems.

Various works testify how efforts have been made to make this integration possible (Baik et al., 2015; Fosu et al., 2015; Ma and Ren, 2017; Liu et al., 2019; Matrone et al., 2019) by proposing various solutions, always referring to the respective open standards (IFC for BIM; CityGML for GIS).

Although BIM and GIS have their specificity, they aim at providing a meaningful and complete description of the site. "The concept of the integration between 3D Building Information Modelling and the 3D Geographic Information System (GIS) provides semantically rich models and allows getting benefits from both systems to help document and analyze cultural heritage sites" (Baik et al., 2015). It is, therefore, necessary to understand how HBIM models can be adequately integrated with those produced in a GIS environment, and how the different data structures can be harmonized and made interoperable with each other, in order to create a single database (DB), to support multiscale analysis on the built heritage and the territory. A series

\footnotetext{
* Corresponding author
} 
of concluded and ongoing research activities try to combine different data coming from devoted DB, BIM, and GIS projects and tries to share the results using web applications.

Most of the web-accessible projects concern GIS systems, as shown by the following examples.

The overall objective of "ResCult Project" (ResCult, 2020) is to enhance the capability of Civil Protection to prevent and mitigate the impacts of disasters on Cultural Heritage sites through the realization of an integrated European Interoperable Database (EID) for $\mathrm{CH}$. The web page allows accessing different EID interfaces (cultural heritage, disasters information, 3d models, risk analysis, advice-seeking, crowd acquiring), according to user account type. GIS-based information about $\mathrm{CH}$ can be shown by data with different geometries, according to CityGML.

"Inception" (Inception, 2020) is a project that involves many organizations that are experimenting BIM in international restoration projects. The project proposes innovative methodologies for the survey and 3D modeling of Cultural Heritage by developing more efficient and cost-effective procedures and methodologies. It is based on the development of an open standard and web-based Semantic Web platform for Building Information Models for Cultural Heritage to contain, implement and share digital models through multi-platform userfriendly interfaces and Augmented Reality applications.

The WebGIS of the Cultural Heritage of Emilia-Romagna, in Italy (Patrimonio culturale, 2014) was born after the 2012 earthquake when it became necessary to prepare cartography related to a database of damaged architectural heritage. The updated databases, coming from MiBACT (Italian Ministry of Cultural Heritage and Tourism) were used, and were progressively georeferenced on cartography (OpenStreetMap, Emilia Romagna Region, and Bing Maps).

Another Italian region (Tuscany) has promoted the "Castore" WebGis project, carried out in collaboration with the Tuscan State Archives, thanks to the agreement signed with the Ministry for Heritage and Cultural Activities (Castore, 2020). The project involved the high-resolution digital replica of over 12,000 nineteenth-century cadastral maps, their filing, and their georeferencing. The maps are accessible via a web application, both as single reproductions of the original archives, with the relative informative sheet, and as a mosaic of georeferenced maps that can be compared with modern cartographies in a Web-GIS environment. The WebGIS site has a dissemination scope in order to facilitate access to geographic information by a broad audience.

"Imago Urbis" is a WebGIS project aimed at collecting and cataloguing all the archaeological data related to the city of Rome and its territory, from the 9th century BC to the 6th century AD. A GIS system has been created to manage the available data. The aims of the project are to know precisely how the city and its neighborhoods have developed over time, to provide a useful tool for the protection of Cultural Heritage and to assist in the future planning of a virtual educational path in Ancient Rome. "Imago Urbis Web-GIS" (Carandini, 2015) allows navigation and consultation of the database to prepare both spatial and alphanumeric analyses.

Still, for the city of Rome, the "WebGIS Descriptio Romae" (Descriptio Romae, 2020) describes the city from the mideighteenth century on the basis of historical cadastral maps, to which contemporary descriptions and additional documents of different kinds are attached.

Other examples of web systems based on historical cartography (cadastral and territorial) aimed at enhancing historical cartographic documentation, supporting sustainable land use and management and/or increasing the awareness of urban modification to enable smart urban planning, are provided by national and international projects such as "GeoPan Atl@s"
(GeoPan Atl@s, 2020), the Catalogue of historical cadasters of Venice (Catalogue of Venice, 2020), "A vision of Britain through time" (A vision of Britain, 2020) and "Carta Historica de Barcelona" (Carta Historica, 2020).

Some relevant examples of web-BIM projects can be found in scientific literature, even though most of them are devoted to new construction. They, prevalently, are solutions that permit to visualize and navigate the model and improve data management (usBIM.platform, 2020; Bimvoyager, 2020; 3DREPO, 2020).

The "HBIM Smart Heritage Building Performance Measurement for Sustainability" project (HBIM, 2020) can be accounted among the few examples of web HBIM. It is an open-source web portal created for expert data management, visualization, and analysis. It combines several demonstrative case studies and their contextual information (heritage reports, measurement surveys, digital sensor data, models, measurement results). The goal of this platform is to be an easily extendible open-source system at disposal for running similar case studies, studying methods for smart performance measurement in heritage buildings, for sustainability and heritage preservation purposes.

Some other ongoing researches proposed to develop and test web tools to share BIM models. For example, the BIMexplorer tool (Quattrini et al., 2017) is conceived to allow non-expert users to perform inquiries over the models and to visualize the results directly on the browser. In this way, the planned maintenance or the restoration project became more collaborative and interactive. A study linked to the European "ResCult project" sought to integrate an HBIM model into a spatial database and to display 3D data in a GIS environment (De Ruvo et al., 2019). The purpose of the study is to investigate the conversion and management of data created as HBIM within a GIS environment, using the IFC and CityGML standards.

These examples show how the research interest is directed towards the integration of the different platforms (BIM and GIS) in a single solution, accessible via the web. However, at the moment, none of the solutions seems to have satisfied the complete integration between the different platforms.

In this context, the paper is based on an extensive research project, carried out in the last eight years at Politecnico di Milano concerning the development of a web information system, named Chimera.

Chimera is the evolution of BIM3DGS (Fassi et al., 2012; Fassi et al., 2015; Rechichi et al., 2016; Tommasi et al., 2019; Achille et al., 2019), a web information system designed explicitly for $\mathrm{CH}$, which can manage multiscale objects, spanning from geographic information up to single and small items such as archaeological finds or paintings.

Chimera has been initially designed to manage cases mainly related to the architectural and archaeological fields, while here its application to an urban context is tested. The focus will be on three main aspects: (i) conceptual data organization to integrate GIS and BIM in a single environment; (ii) integration of data belonging to different historical periods for analyses over time (4D); (iii) integration into the system of datasets already structured in pre-existing HGIS and HBIM.

The analysis will refer to a case study concerning the city of Parma and an extensive datasets of historical cadastral maps, already organized and available in an HGIS (Bruno et al., 2015; Bruno et al., 2016). The paper will present the project according to the following structure: paragraph 2 will address the description of the implemented system Chimera, its main aims, features and capabilities, while paragraph 3 will analyze the use of Chimera in the Parma case study. The available datasets and the already existing HGIS will be analyzed in paragraph 3.1, then the migration of this system to Chimera and results will be exposed and discussed in paragraph 3.2. 


\section{CHIMERA SYSTEM}

Chimera integrates data and objects belonging to the representation scales typical of BIM and GIS in a unique environment and allows managing transversal information. In Chimera, differently from other solutions, (see for instance the one proposed in (Bruno \& Roncella, 2019)) the user has excellent flexibility defining an ad-hoc data structure without a mandatory prior description of which information should be considered more BIM or GIS oriented. This increase significantly the customization of the information infrastructure and allows different purpose users to develop conceptually new ways to use/consult/upgrade the data.

Chimera, therefore, cannot be categorized as a specific GIS or BIM system: rather, it is an information system that goes beyond the distinction between BIM and GIS. It does not contrast with the already existing solutions because it has different functions and purposes: it is a web system, mainly aiming at data entry and data visualization, and is designed for $\mathrm{CH}$ purposes and operators. Chimera is a Web platform that allows the simultaneous use of different data, such as point clouds, 3D meshes, maps, information, images, files etc. The flexibility of Chimera helps in integrating directly also data coming from already existing databases, BIM and GIS system and in avoiding data replicas.

\subsection{Conceptual data organization and 4D management}

Inside Chimera, information is organized according to five hierarchical levels that allow managing different objects according to the investigation purpose, ("GIS-style" or "BIMstyle"). As appropriate, this subdivision can be used in different ways using it, or for a spatial or semantic classification of objects. The original and the first use of the structure is to represent the spatial correlation among the different objects (or spaces) but can also be used to implement a pyramidal semantic classification from general to particular increasing the levels of detail of the 3D representation and of the information content. Where necessary, where the time plays an important role, some of the levels can also acquire a temporal significance giving to the system $4 \mathrm{D}$ capabilities.

Organizing data into levels permits a multiscale approach, moving from a 'single object-element' to 'environmentalelement', and, in the meantime, allows managing all information stored and analyzing each element from a different point of view and at different level of detail.

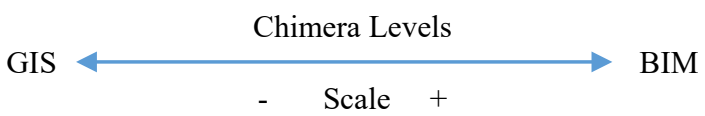

In this way, the purpose is no longer to connect BIM to GIS (or vice versa), nor import/export data between systems, but to find the right level definition. BIM and GIS exist in a single environment and the transition from one to the other is continuous, like a progressive zoom in/out.

Levels allow the natural transition between representation scales, without the need to make replicas of objects at different levels of detail. The same object (e.g. building) is not represented with different levels of detail, but a subsequent level of detail will no longer be the object itself (building), but the objects that make it up (architectural elements).

The level structure is flexible and adaptable to the purpose of each case study. For example, in a purely architectural case study, it is possible to reach even higher levels of detail, while, on the contrary, different levels of detail can be addressed if the objective of the investigation is territorial or urbanistic. In this way the traditional definition "BIM leads and GIS supports" (or vice versa) (Wang et al., 2019) is overcome, because BIM and GIS are on the same level. They can be considered simply two faces, at different representation scale, of a generic information system which links objects (regardless 2D, 2.5D, 3D) and data and keeps track of their evolution over time (4D).

The core entity of the system is the "Object". Each "Object" is the logical reference to the corresponding real object, the unchanging core of the material object over time. To each object, it is possible to associate, even simultaneously, a $3 \mathrm{D}$ or $2.5 \mathrm{D}$ model (mesh, point cloud, hotspot) or a 2D feature (point, line, polygon). Anyway, the system manages concurrently different objects regardless their geometry.

In addition, if an object changes over time, it can be managed through "Versions" and "Sub-versions" Chimera's entities. For each object, there is the possibility to create an unlimited number of Versions and Subversions. The "Version" (of the object) represents different states of the object resulting from events that have modified the object geometry shape. The "Sub-version" (of the object's version) instead represents every state of the object after events that produced changes on information related to the object, but not on its geometry. The events that produce changes in the object, and then the transition from one version (or subversion) to another, are represented in the database by an entity called "Intervention". Information data can be indiscriminately referred to "Objects", "Versions", "Sub-versions" and "Interventions", without limits or constraints in the number of sheets and fields associated. Using Versions, Subversions and Interventions, it is possible to keep track of the future modifications of the object. Also, with this functionality, the system can handle modification over time, assuming 4D capabilities. In fact, according to its structure, Chimera permits modelling object evolution over time (4D) in two ways:

- using structure levels for temporal classification using version and subversion of each object.

Using an initial "time level classification," it is possible to directly access at a specific period and visualize different contemporary data, as in a global view (for instance the state of all object at a specific date). Changing the historical period, it is possible to appreciate time evolution, visualizing the objects (can be not the same object) at different epoch. In this way the various historical periods are displayed as overlapped layers, and their overlay highlights the temporal evolution even from a graphic point of view. The second strategy takes advantage from 'version' and 'subversion'. Opening 'version' and/or 'subversion' it is possible to appreciate the time evolution and modification that occurred on the single object. Using these procedures, the user can extract data information related to the time, in 'vertical' way selecting all necessary levels or in 'horizontal' mode selecting object history stored in 'version' and 'subversion'.

The database of Chimera is a PostgreSQL database with PostGIS extension and includes all the 3D models, the vector 2D data, information, images and files. Also, it can be linked to external repositories (such as Geoserver, map services, etc.) to store GeoTIFF, maps, raster data or GIS elements. The DB structure is very flexible. Object definition and linked information are not predetermined: operations at the administration level let to define several object categories and the number and type of information related to each category.

As a web-system, the functions of data consultation and editing have been privileged over that of modeling, therefore specific tools for $3 \mathrm{D}$ modeling or $2 \mathrm{D}$ drawing have not yet been implemented within the system, and geometrical elements can be imported from external software in file formats such as ESRI Shapefile, .obj, PostGIS database, Geoserver and every WMS sources. The system is able to also import textual information and 
offers the possibility to integrate pre-existing data, already organized and structured in databases.

The strongest point of the system is its customization. It is possible to personalize the platform for each project, through the admin interface and without changing the code. The admins of the project should be able to choose which tables are visible for each category (Objects, Versions, Sub-versions, Models and Interventions). A thorough description of the technical implementation and an in-depth description of specific functions of Chimera can be found in (Rechichi, 2020).

\section{CHIMERA TEST: PARMA HISTORICAL INFORMATION SYSTEM}

\subsection{The case study}

The city of Parma (Northern Italy) has a rich corpus of historical cadastral maps, drawn up continuously since the mid-eighteenth century. Although today it is not one of the main Italian cities by extension, before the Italy Unification, it assumed for a long time the role of capital of a duchy and was one of the first cities, under the influence of cadastral surveying carried out in nearby Piedmont and Lombardy regions, to request the production of a geometrical cadaster.

The principal historical cadasters of Parma are four and refer to a period that spans from 1767 to 1940:

- the Sardi Atlas (1767), drawn by the cartographer Gian Pietro

Sardi during the first Bourbon domination (1749-1804), is the

first geometric cadaster of the city and takes inspiration from the Teresian cadaster of Lombardy;

- the Bourbon Cadaster (about 1853), which corresponds to a revision of the lost Napoleonic cadaster and represents the city between the governments of Marie Louise of Austria and the Duke Charles III of Bourbon;

- the Postunitarian Cadaster (about 1901), which provides a representation of the city after the Unification of Italy;

- the Nuovo catasto edilizio urbano (1940), which photographs the city at the beginning of World War II, after the significant urban development of the early Twentieth Century.

As well known, although cadasters were born as administrative tools with specific tax purposes, combining cartographic and descriptive data, they are an excellent source of architectural, urban planning, economic, demographic etc. information about the city. From their study, it is therefore possible to understand much of the evolution of the entire city and individual buildings. Based on these premises, in 2012 an interdisciplinary project started at the Department of Engineering and Architecture of the University of Parma based on the GIS analysis of these four cadastral sources (Bruno et al., 2015; Bruno et al., 2016).

All the plates have been georeferenced and mosaicked to give a unique image of the city, compliant with the current cartography. Also, the plates of the first two cadasters have been digitized by the vector drawing of polygons corresponding to blocks, parcels and buildings, which are stored in a spatial database. The relational database architecture is based on PostgreSQL, which, with its spatial extension PostGIS, allows managing polygons and related information gathered from the cadastral registers (land/building uses, owners, dimensions, etc.).

The primary purposes of the HGIS were i) the possibility of independent and transversal cadasters consultation, ii) scalable implementation of the system, iii) cost-effective implementation and management, iv) the possibility of query about every single building and about the whole city, using combined data (the type of owner, uses, building types, etc.). The integration with Chimera aims to extend the potential of the system by its extension towards BIM, with the possibility of associating 3D models, point clouds and data of various kinds.
The integration of BIM and GIS information in a single system is beneficial for urban or architectural design, allowing professionals to know both the history of the individual building (changes of ownership, morphological modifications, unifications, additions, demolitions) and the urban context that surrounds it. Greater awareness of such modifications can enable more informed design solutions. Moreover, the possibility of also integrating pre-existing BIM and HBIM systems aimed at planned conservation (Bruno \& Roncella, 2018; Bruno \& Roncella, 2019), allows managing future transformations and interventions on buildings.

\subsection{Development of the Parma Historical Information System}

In the original Parma HGIS project, the database has been designed according to the logical structure imposed by the cadastral sources. From the analysis of sources, information was summarized in three categories: (i) data related to cadasters (general information about each cadaster, plates, registers of owners), (ii) information that can be inferred from the cartography, both those related to the tax purposes that are fundamental for the connection with the registers (blocks, parcels, etc.), and those that can be obtained indirectly from the reading of the contents and drawings (green areas, roads, streams, etc.); (iii) information that can be inferred from the registers, which can be grouped into data relating to parcels, population and road network.

This complexity of information was summarized in the following database main entities: cadasters, registers, plates, blocks, parcels and areas (buildings/yards), which, zooming from the general to particular, constitute a kind of tree. Each parcel, representing the minimum cadastral unit, was related to the owners. This structure made the system consistent and facilitated multi-temporal queries, while the link between objects and cadastral source information made it possible to filter the data and to query each historical period independently.

To integrate the original Parma HGIS into Chimera, information has been migrated into the data structure required by Chimera aiming, as far as possible, not to lose data or waste previous work. First of all, the five logical levels that govern the general structure were identified according to the scheme described in Figure 1 below.

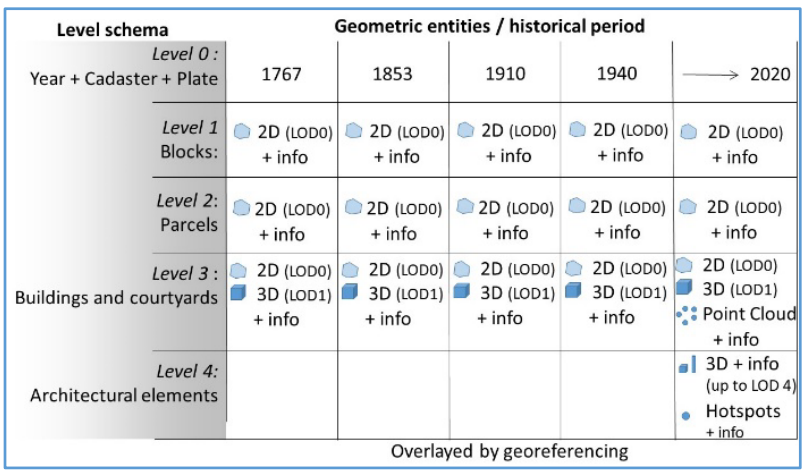

Figure 1. Summary of information per levels and per historic period. LOD are expressed according to CityGML classification.

As it can be seen, the first four levels were assigned to the cadastral data gathered from the original Parma HGIS, while the last one was dedicated to HBIM objects, in order to expand system capabilities and additional link information gathered from 3D models of the buildings. 
In particular, Level 0 corresponds to the union of Historical Period+Cadaster+Plate. This level makes up logical, spatial and temporal classification:

1. Logical, because it identifies which specific plate (of a specific cadaster) an object belongs to;

2. Spatial, because that plate is the representation of a specific geographical zone;

3. Temporal, because each plate and cadaster are specifically related to the year in which they were made.

Since these three entities are purely descriptive without any corresponding geometry, it has been possible to merge them into a single level. In addition to the four historical periods, data related to the current cartography (Open Street Maps and the Technical Cartography of Emilia and Romagna Region) have also been inserted in the system, allowing to know the city up today.

Level 1 corresponds to the blocks, which consist of 2D polygons (Level of Detail - LOD 0) to which the relevant information is associated. Level 2 corresponds to parcels represented by 2D polygons (LOD 0 ) and related information.

Level 3 refers to buildings and unbuilt areas (courtyards or gardens). Also, in this case, the cadastral geometric representation is 2D (LOD 0), while additional 3D representations are linked to each object. The 3D data are different according to the historical reference period, and their realization can be done at different times, depending on the data available for each building. 3D models with a level of detail comparable to CityGML LOD 1 can be made for all historical periods by extrusion of the building perimeter. For older periods, information on the height of buildings can be derived approximately from land registers (e.g. by indicating the number of floors) or from integration with data from other sources such as building permits, perspective views, etc. For more recent epochs, however, this information is already present in technical cartography such as that used in this work.

The 3D representation of the city, even if simplified, allows to understand the volumetric transformations of buildings and to reconstruct their evolution, as in a "3D time machine".

In addition to models, only for the current period, point clouds describing the current state of the building can be linked. Point clouds resulting from 3D surveying are a faithful 3D representation of the building, and their presence within the system allows the user to have dimensional information assisting $3 \mathrm{D}$ conceptualization and modeling procedure.

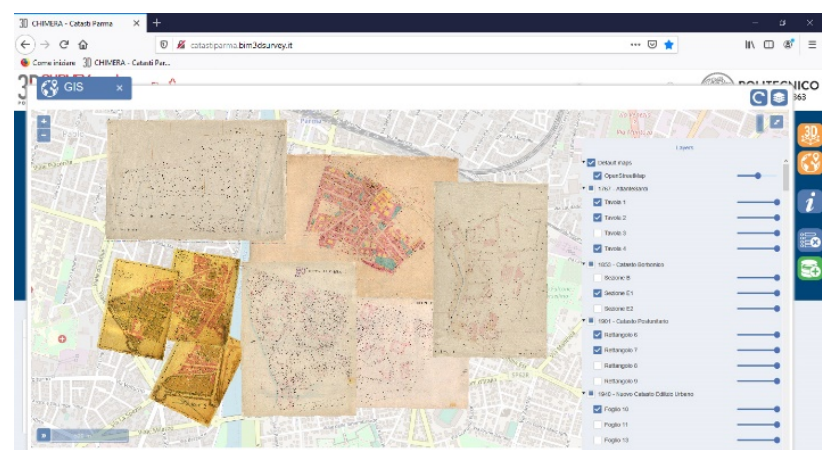

Figure 2. Example of 2D map data visualization within the system. Some layers belonging to Level 0 but referring to different periods are displayed. Each layer can be switched on and off and its transparency can be adjusted.

Level 4 relates to more detailed architectural objects which compose the current state of the buildings and can correspond up to CityGML LOD 4. At this level 3D models of the individual architectural elements or hotspots are inserted, to which the typical BIM information is linked.

Up today, the current cartography, all the geo-referenced historical maps and the polygons representing blocks, parcels and buildings belonging to 1767 and 1853 period (as in the original Parma HGIS) have been entered (Figure 2). 3D models (Level 3) of the entire current city have been loaded, while for previous periods only models of unchanged buildings over time have been made, while specific research is underway for the others. As far as Level 4 is concerned, data relating to two of the city's most important monuments have been entered in the system: the point cloud obtained by laser scanner survey of the Romanesque Cathedral and the 3D model of the Baptistery.

Concerning the attributes, the data available from the land registers have been entered and linked to their corresponding objects. For example, the parcels have been associated with descriptive data (tax purpose data, extension, use, etc.) and data relating to the owners (name, surname, title, profession, etc.). Additional information will be linked to $3 \mathrm{D}$ models and point clouds, as soon as the current surveys make them available.

Multi-temporal data have been managed using a "level strategy", as can be seen from the level structure at the beginning of this paragraph because we were interested in presenting the image of the whole city in a specific historical period. In addition, the system enables to query simultaneously all the active layers. In

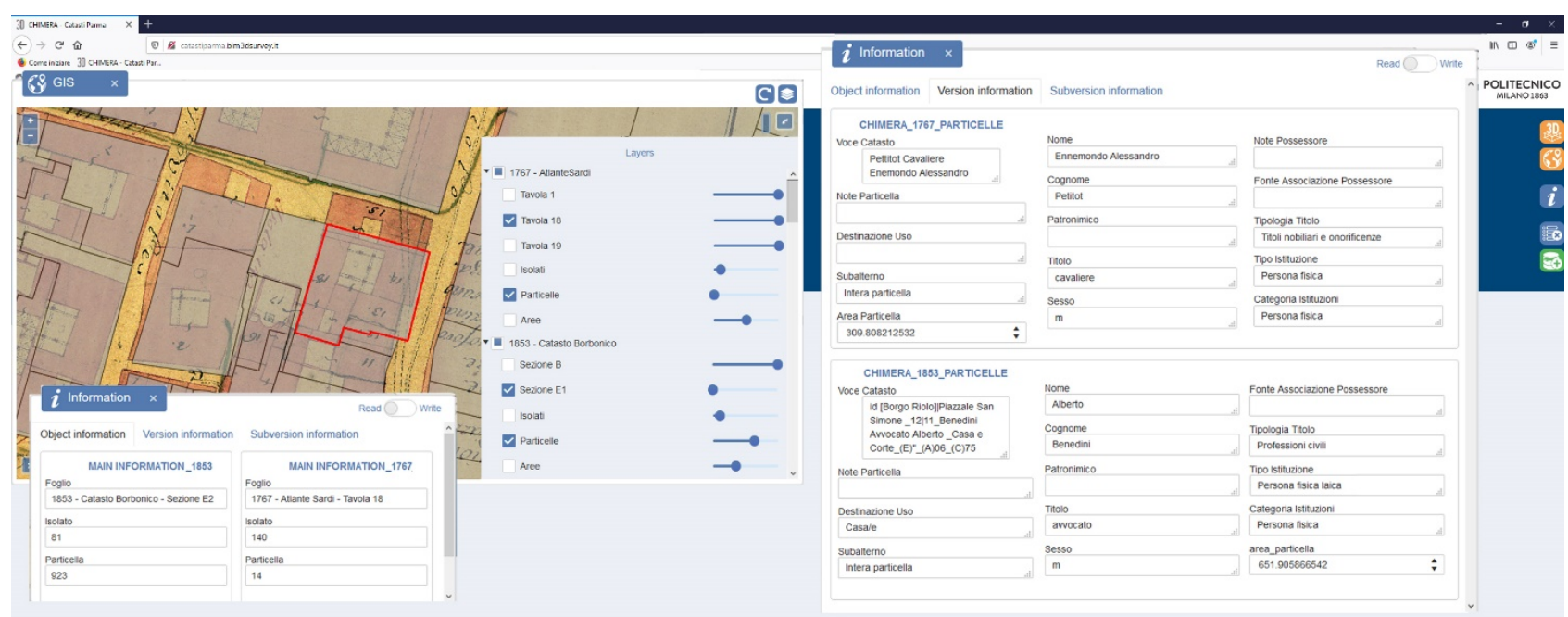

Figure 3. Example of multi-temporal query. The raster map refers to 1767 while the vector polygons represent parcels in 1853 . The spatial overlap shows the transformations occurred, while the attribute sheet shows the information related to the selected parcel in the two historical periods. 


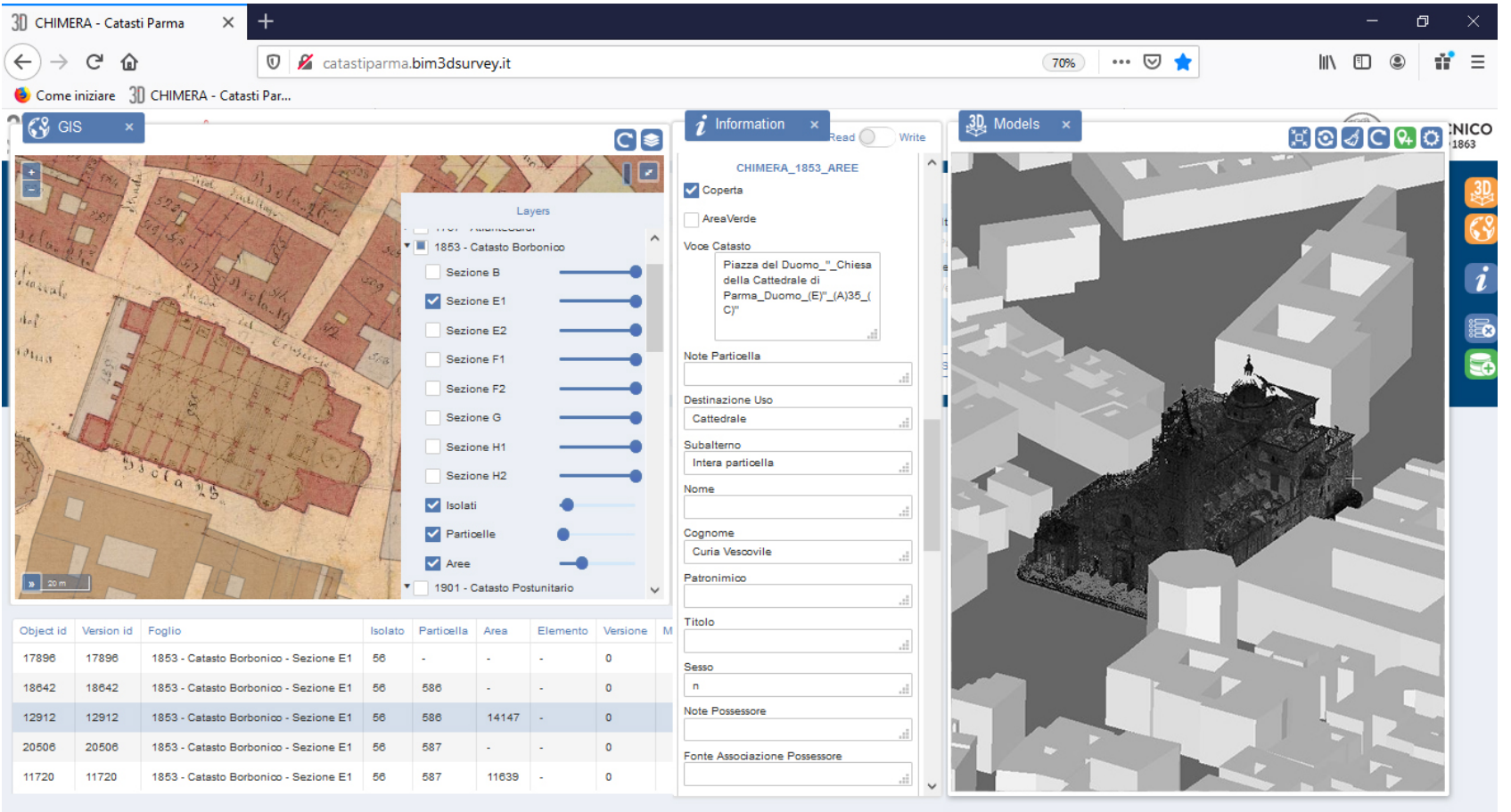

Figure 4. Image shows data about the Cathedral. On the left, the 2D interface displays the 1853 historical map, with vector polygons representing blocks, parcels and buildings superimposed as layers with different transparency. In the center, the data sheet shows information referred to the Cathedral in 1853. On the right, the 3D model (LOD1) of the whole city and the 3D point cloud of the Cathedral, referring to the current period, are displayed.

this way, simply by selecting a point on a map it is possible to see data belonging to different periods referred to that point (Figure 3). 'Versions' and 'Subversions' can be used in parallel, for example, to keep track of the changes that have occurred to a specific building between two epochs, as far as the information is available, or the future transformations that each building will undergo.

Since it was not possible to import tables and relations into the new system as they were, the migration of this data from Parma HGIS to Chimera required to query the original database and join the tables, to have the data directly associated with the objects in Chimera (blocks, parcels and buildings). This was a simple operation that allowed migrating data without setting up the database from scratch.

The only two things that had to be sacrificed were some normalizations made on the data and the management of some many-to-many relationships. For instance, not to duplicate the parcels, the many-to-many association with the owners has been lost. In fact, the system does not yet support the management of this relationship and is currently able to manage unique field values, so only one owner can be associated as an attribute.

The actual migration of data between systems was quite straightforward: the georeferenced maps were uploaded as GeoTIFF to a shared, web-accessible Geoserver repository. In order to ensure correct overlap with Open Street Maps layer, used in Chimera as reference map layer for the current city, a conversion of the reference system from EPSG 23032 to EPSG 3857 was necessary and was carried out directly in Geoserver. Since all data are related to each other and coexist in a single environment, searches can be done with three different access modes: textual object search, GIS map navigation and object selection on the 3D model. Textual data (information about elements), images, 3D models, 2D raster and vector maps can be displayed in parallel in integrated and synchronized floating windows (see Figure 4 and Figure 5 where examples of queries about the Cathedral and the Baptistery are shown). Such simple and easy to use graphical user interface simplifies data consultation also for less digital skilled users or professional not experienced in BIM and GIS use. In addition, the web-based architecture simplifies data interoperability, accessibility and retrieval from any device.

\section{CONCLUSIONS}

Chimera was not designed to replace traditional GIS and BIM platforms but to place them side by side.

GIS originally have been developed from the need to collect, process, manage and make available a huge amount of data and information relating to the territory. BIM systems have been originally realized, on the contrary, to support informed decisions in the field of architectural design.

Over the past two decades, the transition from traditional representation on paper to information systems (GIS or BIM) has completely changed the way we read the territory and the buildings. The possibility of inserting/overlapping an impressive amount of data has led to the progressive adoption of these systems, in the idea that an 'encyclopedia' could be created for each specific need. However, the practical impossibility of representing everything and often the uselessness of having specific data has often led to the construction of GIS-BIM projects that are not very functional for the purpose. Analysis and decisions deriving from the use of GIS and BIM processes must be based on accessible, updated and, above all, relevant data for the purpose.

In this sense, the use of the Chimera platform is thought not so much as an 'alternative' or 'modern duplicate' of existing databases, but as an effective method of accessing and consulting data. The data already collected in previous and ongoing GIS and HBIM projects are linked through a sophisticated DB and made accessible/searchable through a web-accessible interface. In this sense Chimera is interoperable.

Chimera applied to Parma city case study allows the convergence of all types of data relating to the historical and current context of the city. Parma is a significant case study for the availability 


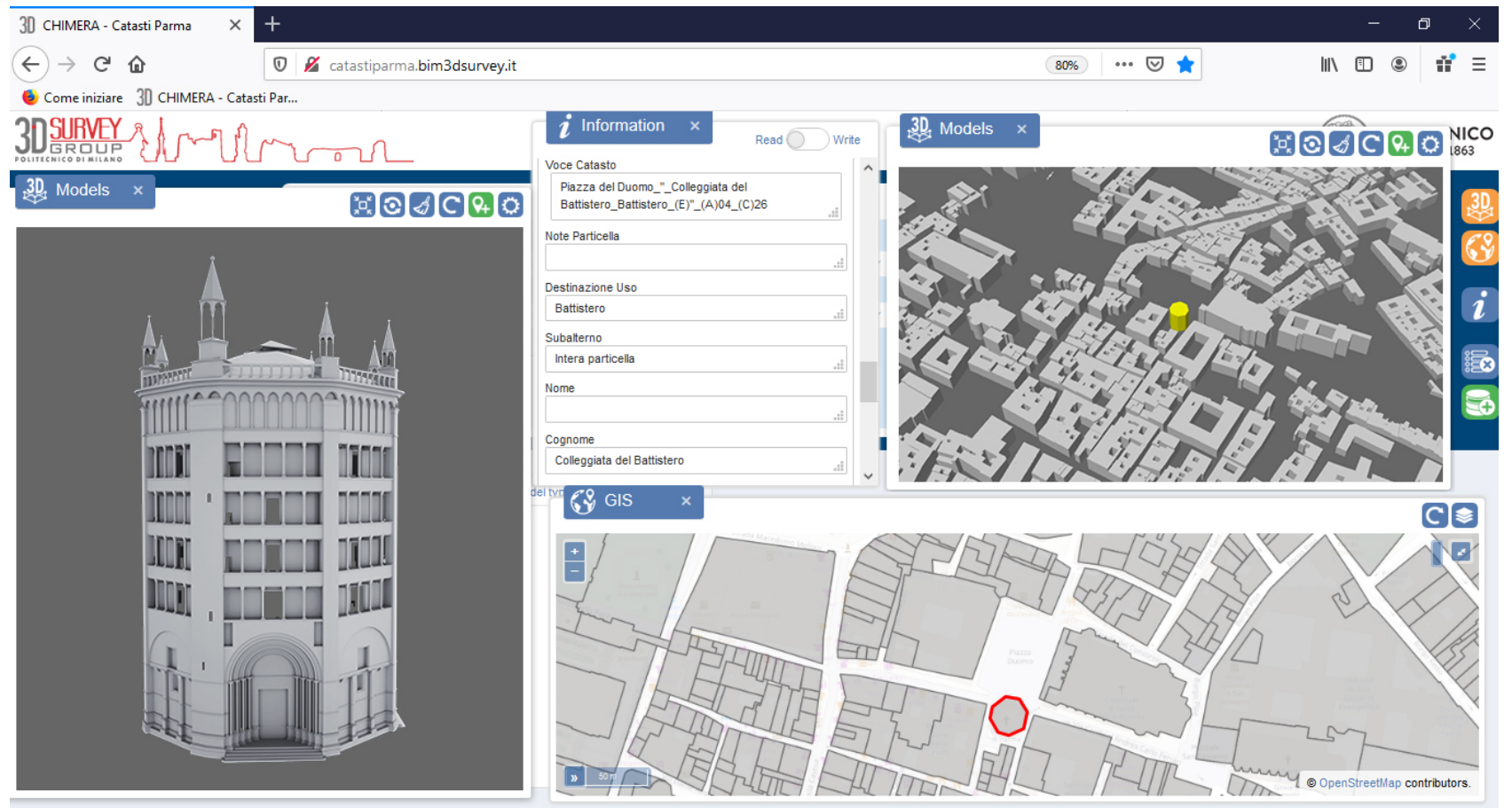

Figure 5. Image shows data referred to the Baptistery: 2D map, 3D at LOD 1, 3D at LOD 4 and data related to the selected elements.

of a large amount of cartographic data and a highly detailed HBIM model that permitted to test the Chimera performance. The realized platform allows both horizontal (time) and vertical (stratification of information) comparison of data (paragraph 2.1), concerning the various types of available information, in particular the real multiscale cross-correlations. In fact, the benefit offered by this platform is the possibility to simultaneously show objects at cartographic scale with others at the architectonical scale, in the same environment. This option allows seeing Parma from a different point of view, selecting time by time what is necessary to better understand the evolution process of a single building, district, and entire city. This is particularly interesting when you have to face with a historical urban environment where it is mandatory to understand the building evolution and contemporarily consult specific and detailed urban or historical data.

In the near future, the progressive increase of data and models will make it possible to have a web platform able to support the different needs of the many operators who can benefit from such a system. For example, public administrations and superintendencies can have benefit during the planning interventions at an urban level. They can check the heritage building position and condition (HBIM data) and simultaneously acquire information about cadastral maps information, helped by cross-correlated data and comparison thematic maps.

Another use of the system can be historical, to understand the single building evolution, comparing and merging data coming from different documents. This is another possibility to use the system of a centralized archive as a complete collector of technical (as building paperwork, technical drawing or 3D models) or more general or historical documents.

Some other beneficiaries can be professionals, as urban planners and restorers, that have the possibility to demonstrate how portions of the city have evolved and to compare the existing condition with the previous states of the building under intervention.

The main benefits concern the possibility of creating a broader and more in-depth understanding of the urban context, using at the same time the spatial information typical of the available GIS databases and the HBIM data of the building, simultaneously managing multiscale model and related information.

Having as a reference the geo-referenced cartographic and cadastral maps, the Parma Historical Information System allows to quickly obtain the most relevant territorial information for the projects/researches in progress. On the other hand, the numerous information linked to the HBIM model can be usefully integrated, offering a viewpoint 'at detailed scale', finding application in urban analysis and planning.

Today "Web-platform" means sharing and consult data without specific software technical skills; this possibility increases the number of people that can try to benefit from this kind of tools. In this sense, Chimera is a great resource, but it requires a mandatory and deep design of the connection between existing data and new ones. It looks obvious, but identifying aims and target users is essential to properly and profitably set up a web information platform.

\section{ACKNOWLEDGEMENTS}

The authors would like to acknowledge Sandra Mikolajewska for the Baptistery 3D model at LOD 4.

\section{REFERENCES}

3DREPO, 2020. https://3drepo.com/ (Last accessed April 2020).

A vision of Britain, 2020. https://www.visionofbritain.org.uk (Last accessed April 2020).

Achille, C., Tommasi, C., Rechichi. F., Fassi F., De Filippis, E., 2019. Towards an advanced conservation strategy: a structured database for sharing 3D documentation between expert users. Int. Arch. Photogramm. Remote Sens. Spatial Inf. Sci., XLII-2/W15, 9-16.

Baik, A., Yaagoubi, R., Boehm, J., 2015. Integration of Jeddah historical BIM and 3D GIS for documentation and restoration of 
historical monument. Int. Arch. Photogramm. Remote Sens. Spatial Inf. Sci., XL-5/W7, 29-34.

Bimvoyager, 2020. https://bimvoyager.accasoftware.com/it/ (Last accessed April 2020).

Bruno, N., Bianchi, G., Zerbi, A., Roncella, R., 2015. An openHGIS project for the city of Parma: database structure and map registration. Free and Open Source Software for Geospatial Open Innovation for Europe. GEOMATICS WORKBOOKS, Como, Italy, vol. 12, p. 189-203.

Bruno, N., Previtali, M., Barazzetti, L., Brumana, R., and Roncella, R., 2016. A virtual hub brokering approach for integration of historical and modern maps. Int. Arch. Photogramm. Remote Sens. Spatial Inf. Sci., XLI-B4, 163-170.

Bruno, N. and Roncella, R., 2018. A restoration oriented HBIM system for cultural heritage documentation: the case study of Parma Cathedral. The International Archives of the Photogrammetry, Remote Sensing and Spatial Information Sciences, Vol. XLII (2), pp. 171-178.

Bruno, N. and Roncella, R., 2019. HBIM for Conservation: A New Proposal for Information Modeling. Remote Sens. 2019, 11, 1751.

Carandini, A., 2015. Imago urbis - Lazio, Roma e suburbio, Roma archeologica \& restauro architettura, La Sapienza Universita` di Roma Review of "Atlante di Roma antica" (2013) by: Wiseman \& Packer (2013).

Carta Historica de Barcelona, 2020. http://ajuntament. barcelona.cat/museuhistoria/cartahistorica/\#map=13/239777.44/ 5069248.16/2010//0/0/0/0 (Last accessed April 2020).

Castore, 2020. Catasti storici regionali. https://www. regione.toscana.it/-/castore (Last accessed April 2020)

Catalogue of Venice, 2020. http://geocataloghi1.iuav.it/catasti_ storici.html (Last accessed April 2020).

De Ruvo, V., Colucci, E., Matrone F., Lingua, A., Spanò A., 2019. HBIM in un database GIS 3D semantico. In Atti della Conferenza Asita 2019.

Descriptio Romae, 2020. http://www.dipsuwebgis.uniroma3. it/site/ws/ (Last accessed April 2020).

EUPPD 2014/24, European Union Public Procurement Directive, n. 24,2014

Fassi, F., Parri, S., 2012. Complex Architecture in 3D: From Survey to Web. International Journal of Heritage in the Digital Era, Vol. 1, p. 379-398 ISSN: 2047-4970.

Fassi, F., Achille, C., Mandelli, A., Rechichi, F., Parri, S., 2015. A new idea of BIM System for visualization, web and using huge complex 3D model for facility management Int. Arch. Photogramm. Remote Sens. Spatial Inf. Sci., XL-5/W4, 359-366.

Fosu, R., Suprabhas, K., Rathore, Z., Cory, C., 2015. Integration of Building Information Modeling (BIM) and Geographic Information Systems (GIS) - a literature review and future needs, Proceedings of the 32nd CIB W78 Conference 2015, 196-2014.
GeoPan Atl@s, 2020. http://geoserver.atlas.polimi.it/examples /servlets/Geopan/D/web/index.html (Last accessed April 2020).

HBIM, 2020. http://www.hbim.org/ (Last accessed April 2020)

Inception, 2020. https://www.inception-project.eu/ (Last accessed April 2020)

ISO 19650-1,2:2018. Organization and digitization of information about buildings and civil engineering works, including building information modelling (BIM) - Information management using building information modelling. Parts 1-2.

Liu, Z., Lu, Y., Peh, L.C., 2019. A Review and Scientometric Analysis of Global Building Information Modeling (BIM) Research in the Architecture, Engineering and Construction (AEC) Industry. Buildings 2019, 9, 210.

Ma, Z. and Ren, Y., 2017. Integrated Application of BIM and GIS: An Overview. Procedia Engineering, 196, 2017, 10721079.

Matrone, F., Colucci, E., De Ruvo, V., Lingua, A., and Spanò, A., 2019. HBIM in a semantic 3D GIS database. Int. Arch. Photogramm. Remote Sens. Spatial Inf. Sci., XLII-2/W11, 857865.

Quattrini, R., Pierdicca, R., Morbidoni, C., Malinverni, E., 2017. Conservation-oriented HBIM. The bimexplorer web tool. Int. Arch. Photogramm. Remote Sens. Spatial Inf. Sci., V XLII-5/W1, 275-281.

Patrimonio culturale, $2014 \mathrm{https} / /$ www.patrimonioculturaleer.it/webgis (Last accessed April 2020)

Rechichi, F., Mandelli, A., Achille, C., Fassi, F., 2016. Sharing high-resolution models and information on web, the web module of BIM3DSG system. Int. Arch. Photogramm. Remote Sens. Spatial Inf. Sci. XLI-B5, 703-710.

Rechichi, F., 2020. CHIMERA: A BIM+GIS System for Cultural Heritage. Int. Arch. Photogramm. Remote Sens. Spatial Inf. Sci. In press, 2020.

ResCult, Increasing Resilience of Cultural heritage: a supporting decision tool for the safeguarding of cultural assets https://www.rescult-project.eu/ (Last accessed April 2020)

Tommasi, C.; Achille, C.; Fanzini, D.; Fassi, F., 2019. Advanced digital technologies for the conservation and valorisation of the UNESCO Sacri Monti, in Vol. 1 - Digital transformation of the design, construction and management processes of the built environment, Springer 2019 ISBN: 978-3-030-33570-0

UNI11337-1/2017. http://store.uni.com/catalogo/uni-11337-12017. (Last accessed April 2020).

us.BIMplatform 2020, https://www.acca.it/bim-collaborationsoftware (Last accessed April 2020)

Wang, H., Pan, Y., Luo, X., 2019. Integration of BIM and GIS in sustainable built environment: A review and bibliometric analysis, Automation in Construction, 103, 2019, 41-52. 